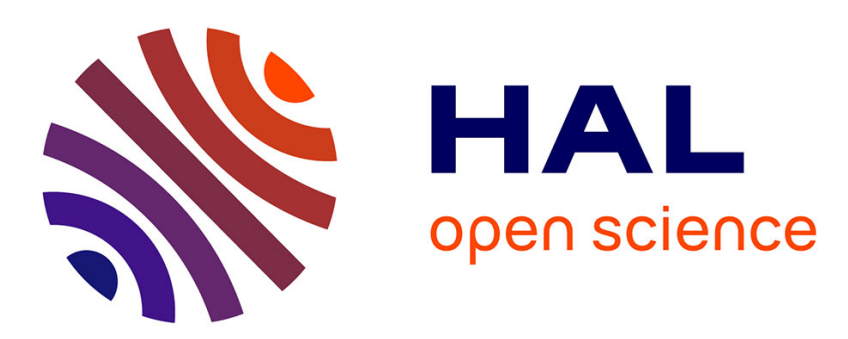

\title{
The role of triggering by static stress transfer during geothermal reservoir stimulation
}

\author{
M. Schoenball, C. Baujard, T. Kohl, L. Dorbath
}

\section{To cite this version:}

M. Schoenball, C. Baujard, T. Kohl, L. Dorbath. The role of triggering by static stress transfer during geothermal reservoir stimulation. Journal of Geophysical Research: Solid Earth, 2012, 117 (B9), pp.1978-2012. 10.1029/2012JB009304 . hal-00933150

\section{HAL Id: hal-00933150 \\ https://hal.science/hal-00933150}

Submitted on 16 Jun 2021

HAL is a multi-disciplinary open access archive for the deposit and dissemination of scientific research documents, whether they are published or not. The documents may come from teaching and research institutions in France or abroad, or from public or private research centers.
L'archive ouverte pluridisciplinaire HAL, est destinée au dépôt et à la diffusion de documents scientifiques de niveau recherche, publiés ou non, émanant des établissements d'enseignement et de recherche français ou étrangers, des laboratoires publics ou privés. 


\title{
The role of triggering by static stress transfer during geothermal reservoir stimulation
}

\author{
M. Schoenball, ${ }^{1,2}$ C. Baujard, ${ }^{2}$ T. Kohl, ${ }^{1}$ and L. Dorbath ${ }^{3}$ \\ Received 13 March 2012; revised 27 July 2012; accepted 30 July 2012; published 20 September 2012.
}

[1] During creation of an Enhanced Geothermal System, massive fluid injections are conducted to induce fracture shear which generates reservoir permeability. In this study we analyze coseismic static stress transfer caused by induced seismic events during a stimulation at the European research project at Soultz-sous-Forêts (Alsace, France). For this purpose we developed an efficient method to calculate coseismic static stress changes from an elliptical slip distribution on a circular fracture using superposition of rectangular sources, which enables us to apply an analytical solution for fast computation. This method is applied on a data set of 715 focal mechanisms derived from seismic recordings of the stimulation of the well GPK2 to calculate temporal evolution of static stress transfer. We find that the resulting structure of coseismic stress changes can be divided into three parts: a quiet zone where no spreading of seismicity occurs, an active zone within the created reservoir with ongoing fracturing and a process zone where the growth of the reservoir occurs. Static stress changes in the active zone are of the order of $1 \mathrm{MPa}$, both positive and negative, but may exceed this value considerably on a local scale. Analysis of stress changes from a cluster of events that occurred after shut-in lets us conclude that triggering by coseismic static stress changes is possible for some events. Our analysis shows that triggering by static stress transfer plays a minor role for injection induced seismicity in a volumetric reservoir, whereas it can be quite effective for rupture propagation along single large fault zones.

Citation: Schoenball, M., C. Baujard, T. Kohl, and L. Dorbath (2012), The role of triggering by static stress transfer during geothermal reservoir stimulation, J. Geophys. Res., 117, B09307, doi:10.1029/2012JB009304.

\section{Introduction}

[2] The phenomenon of fluid induced seismicity is widely observed and may impose barriers for future large scale operation of EGS plants [Evans et al., 2012]. For the prediction of future reservoir performance, knowledge of the thermo-hydro-mechanical response of the geothermal reservoir to hydraulic stimulation and production is a key issue. In previous studies on the mechanisms of induced seismicity the focus was mainly on the role of the pore pressure perturbation or thermal stresses [Bruel, 2002; Shapiro et al., 2002; Kohl and Mégel, 2007]. Little attention was paid to the possible interaction of such events. However, in the field of seismology of tectonic earthquakes, interaction of

\footnotetext{
${ }^{1}$ Institute for Applied Geoscience, Karlsruhe Institute of Technology, Karlsruhe, Germany.

${ }^{2}$ GEOWATT AG, Zürich, Switzerland.

${ }^{3}$ Ecole et Observatoire des Sciences de la Terre, University Louis Pasteur, Strasbourg, France.

Corresponding author: M. Schoenball, Institute for Applied Geoscience, Karlsruhe Institute of Technology, Kaiserstr. 12, D-76131 Karlsruhe, Germany. (martin.schoenball@kit.edu)

(C)2012. American Geophysical Union. All Rights Reserved. 0148-0227/12/2012JB009304
}

earthquakes has gained significant attention. Aftershock sequences for tectonic earthquakes could be described as induced by changes of static stress due to the dislocation by the main shock [e.g., King et al., 1994; Toda and Stein, 2003]. The basis for such modeling was laid by Okada [1992], who derived analytical expressions for the displacements in an elastic half space caused by dislocations on a fault plane. Based on these stress changes and e.g. a rate and state law for seismicity rates [Dieterich, 1994] aftershock sequences could be modeled successfully [Toda and Stein, 2003; Catalli et al., 2008]. Apart from modeling of aftershock sequences, migrating seismicity on large faults could be explained by interaction of events [e.g., Stein et al., 1997], where increases of stress arising at the edge of the slipping plane triggered failure at neighboring fault patches.

[3] Orlecka-Sikora et al. [2009] analyzed coseismic static stress changes and interaction of induced seismicity in a Polish coal mine environment. They observed that about $60 \%$ of events are located in areas where Coulomb stress changes encouraged failure and 50\% in areas where the stress perturbation by static stress transfer surpassed $0.01 \mathrm{MPa}$, a value which is a generally accepted threshold perturbation for triggering of natural earthquakes [Hardebeck et al., 1998; Prejean et al., 2004; Xiong et al., 2010]. While Orlecka-Sikora et al. [2009] and this study focus on triggering by static stress 
changes, it shall be noted that dynamic triggering by the passing wave train has also been observed [e.g., Felzer and Brodsky, 2006; Prejean et al., 2004].

[4] Phillips et al. [2002] performed a multiplet analysis and relative relocation of events induced during a stimulation operation in 1993 at Soultz-sous-Forêts and five other geothermal and hydrocarbon sites. From high precision relative locations they concluded that slip induced changes of static stress migrate seismicity along larger fault planes at hydrocarbon sites and state that such slip-induced stress could cause systematic migration of seismicity also at Soultz. Dorbath et al. [2008] studied static stress changes due to the microseismic events of the stimulation of the well GPK2 in the year 2000, by approximating the microseismic cloud with one unique plane. Using this approach, they found a shift in the azimuth of the faults optimally oriented for failure in two different depth zones of the reservoir. This result is in agreement with the observation of a change of the orientation of the microseismic cloud produced by the later stimulation of the well GPK3 in 2003. However, their hypothesis that the microseismic activity in the reservoir could be depicted by one single fault has not been validated.

[5] In this paper we present $3 \mathrm{D}$ computations of change of static stress during the stimulation of the well GPK2 at the EGS site Soultz-sous-Forêts to analyze the mechanical interaction of induced events. For this analysis we use an extensive database of 715 derived focal mechanisms [Dorbath et al., 2009]. In order to find a computationally efficient way to approximate circular sources taking into account an elliptical slip distribution, we test various idealized fault plane geometries. We then compute the time evolution of static stress changes due to events in the Soultz reservoir during the stimulation of the well GPK2. This allows us to conclude that the stress perturbation of all microseismic events induced during stimulation cannot be depicted by one single fault, but varies strongly on a local scale. Analysis of a cluster of 12 events, which occurred at the edge of the stimulated volume, demonstrates the effectiveness of static stress triggering for the propagation of seismicity along faults.

\section{Data Description}

[6] At the European deep geothermal research project at Soultz-sous-Forêts (Alsace, France) [Genter et al., 2010] four wells were drilled to $5 \mathrm{~km}$ depth in a horst structure within the granite basement of the Upper Rhine Graben. In order to develop an Enhanced Geothermal System (EGS) several well stimulations have been conducted in order to enhance the reservoir productivity [Dorbath et al., 2009]. These operations were accompanied by thousands of induced microseismic events. During the stimulation of the well GPK2 about $25,000 \mathrm{~m}^{3}$ of fresh water were injected with flow rates of 30 to $501 \mathrm{~s}^{-1}$ over a duration of 6 days [Weidler et al., 2002]. The stimulation of GPK2 was seismically recorded by both a down-hole and a surface network of seismometers. About 14,000 events could be located by the down-hole network [Dyer, 2000], from which three stations with 4-component accelerometers at about $1500 \mathrm{~m}$ depth (i.e. at the top of the granitic basement) were used for analysis. The temporary surface network consisted of 14 stations, 6 with 3-component velocimeters and 8 with 1-component vertical velocimeters. For further details on the monitoring network we refer to
Dorbath et al. [2009]. Our input data consists of 715 focal mechanisms of events induced during and immediately after the stimulation of GPK2 with magnitudes $>1$ [Dorbath et al., 2009], for which relatively good signal-to-noise ratio waveforms were obtained from both networks. The microseismic sequence used does not contain the largest events induced during the operation with magnitudes 2.6 and 2.7, respectively. They occurred long after shut-in when the temporary monitoring network was already removed from the field. The hypocenter locations were obtained using a modified version of HYPOINVERSE [Klein, 1978] and station corrections. Uncertainties are about $50 \mathrm{~m}$ in horizontal and $70 \mathrm{~m}$ in vertical directions. Event magnitudes, $M_{W}$, were calculated from the duration of the coda [Charléty et al., 2007]. To calibrate this duration magnitude, Charléty et al. [2007] determined the moment magnitude for several events with magnitudes in the range $0.7-2.9$ using waveforms with good signal-to-noise ratio recorded during the stimulation of the well GPK3 in 2003. The seismic moment, $M_{0}$, was calculated from $M_{W}$ using Kanamori [1977]:

$$
M_{W}=\frac{\log M_{0}}{1.5}-6.07 .
$$

Slip could then be derived from

$$
M_{0}=G S d,
$$

where $G$ is the shear modulus, $S$ is the surface area of the fault plane and $d$ is the average displacement. The ratio of displacement to surface area is determined by the stress drop $\Delta \sigma$. Following the relation of Eshelby [1957] for stress drop $\Delta \sigma$ on a circular rupture of radius $r$,

$$
\Delta \sigma=\frac{7 \pi}{16} \frac{G d}{r}=\frac{7 \pi}{16} \frac{M_{0}}{r^{3}},
$$

the fault radius and the displacement can be determined using a stress drop value together with equation 2. Stress drops from fluid induced events have been analyzed for the injection experiments at the KTB project [Jost et al., 1998] and at the Basel Deep Heat Mining project [Goertz-Allmann et al., 2011]. For the Soultz reservoir, stress drops and source dimensions have been studied by Charléty et al. [2007]. In general agreement with the previously mentioned studies at KTB and Basel, Charléty et al. [2007] found the stress drop to vary between $0.1 \mathrm{MPa}$ and $10 \mathrm{MPa}$. We use the previously mentioned studies as a basis for a statistically distributed value of $\Delta \sigma$. We use a constant log-mean value of $1 \mathrm{MPa}$ for the following study; the influence of variable stress drop on the significance of the results is discussed below. The method to differentiate the fault plane and the auxiliary plane from the two nodal planes given by the focal mechanism is described in section 3. Figure 1 shows the events and their fault planes derived by the procedure above.

[7] Elastic rock properties have been assumed in agreement with the previous study by Dorbath et al. [2008], i.e. a shear modulus of $G=32 \mathrm{GPa}$ and a Poisson's ratio $v=0.25$. The coefficient of friction is assumed to be 0.8 , which is the lower estimate of the two models developed by Cornet et al. [2007]. A comparison of density of fracture normals in the three wells GPK2-4 obtained from UBI wellbore logging with those of the fracture planes from focal mechanisms is given in 

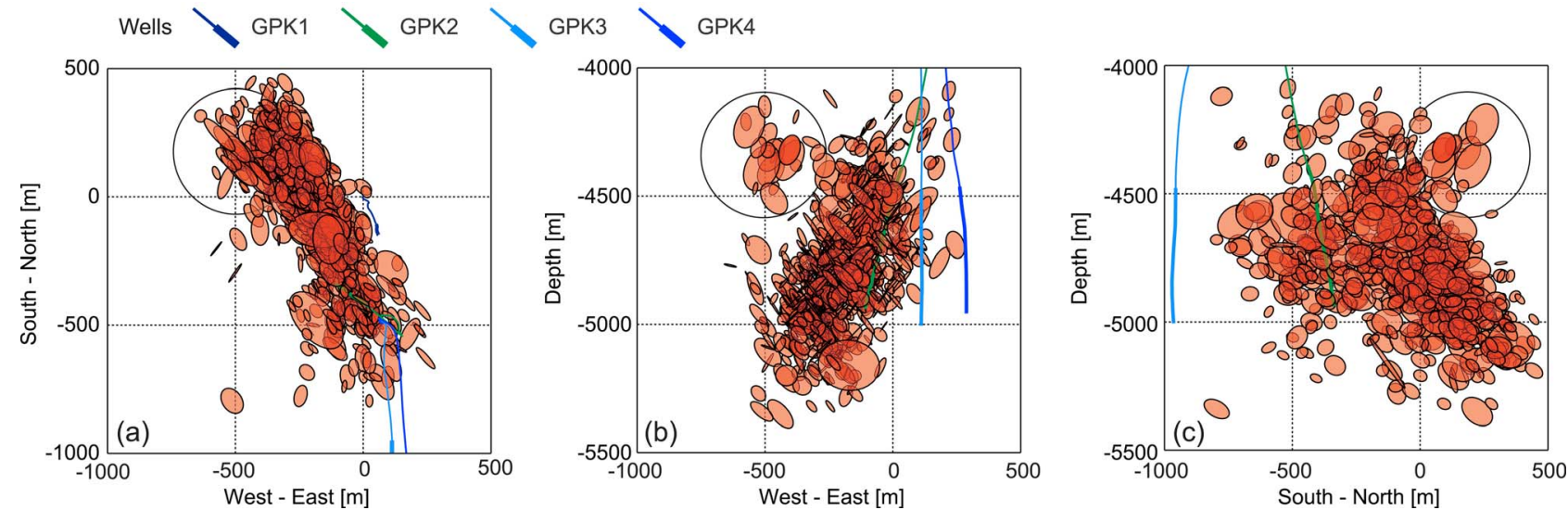

Figure 1. (a) Map view and (b, c) depth views of the fault planes obtained from focal mechanisms. The circles mark a cluster of events discussed in section 5.3.

Figures 2a-2c. These plots show two major fracture families dominating the reservoir (average orientations are strike $\mathrm{N} 180^{\circ} \mathrm{E}$, dip $80^{\circ}$ and strike $\mathrm{N} 335^{\circ} \mathrm{E}$, dip $80^{\circ}$, respectively). Note the slight counter-clockwise rotation of average azimuth with depth (Figures 2a vs 2c). The fracture families are also evident in the fault planes derived from the focal mechanisms (Figure 2d). The focal mechanisms are in better agreement with the deeper fractures, which consistent with the greater depth of the focal mechanisms. The focal mechanisms have generally lower dip angles than the fractures identified in the wellbore image logs.

\section{Method}

[8] The displacement field in a homogeneous elastic half space due to a dislocation on a rectangular fault has been analytically derived by Okada [1992]. We use a code based on the software EDCMP [Wang et al., 2003] to calculate the displacement field in the reservoir as it evolves through subsequent microseismic events during the stimulation. Having obtained the displacement field $u$ from Okada's solutions, the strain tensor $\epsilon$ is readily obtained from

$$
\epsilon_{i j}=\frac{1}{2}\left(\frac{\partial u_{i}}{\partial x_{j}}+\frac{\partial u_{j}}{\partial x_{i}}\right)
$$

(a)

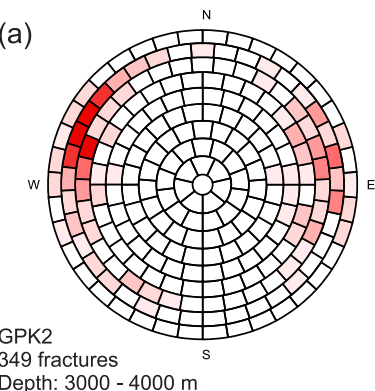

(b)

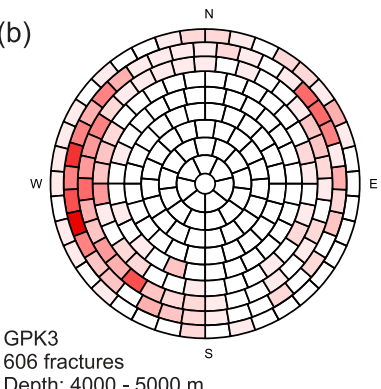

We assume a linear elastic medium by applying Hooke's law to obtain the change of the stress tensor from the strain tensor. To express the effect of changes to the stress tensor on the occurrence of failure by a single quantity, the concept of Coulomb failure stress is commonly applied. Following this concept, failure occurs if the Coulomb stress $\sigma_{c}$ exceeds a critical value [King et al., 1994] given by

$$
\sigma_{c}=|\tau|-\mu(\sigma-p),
$$

where $\tau$ is the shear stress on the plane in consideration, $\sigma$ is the corresponding normal stress, $\mu$ is the coefficient of static friction and $p$ is the pore fluid pressure. In this paper our focus is on stress changes due to dislocations, so we do not consider changes of pore fluid pressure. Furthermore we neglect any poroelastic interaction of stress and pore fluid pressure, which would introduce minor transient effects. Finally we obtain for changes of Coulomb failure stress

$$
\Delta C F S=\Delta \tau-\mu \Delta \sigma,
$$

where $\Delta \tau$ is the change of the absolute value of shear stress and $\Delta \sigma$ is the change of normal stress on the fault plane considered. In this concept a positive value of $\triangle \mathrm{CFS}$ means that the point considered is driven toward failure whereas for a negative $\triangle \mathrm{CFS}$ stress is released and consequently failure is hindered.

Figure 2. Distribution of fracture plane normal densities in a lower hemisphere projection, where a point in the center indicates a horizontal fracture while a point near the outer edge is a vertical fracture with dip direction as indicated on the edge. $(\mathrm{a}-\mathrm{c})$ Fractures obtained from UBI logs of GPK2, GPK3 and GPK4, (d) the focal mechanisms of the stimulation of GPK2. The color shows the relative density of fractures where each segment is of equal solid angle [after Meller et al., 2012]. 
(a)

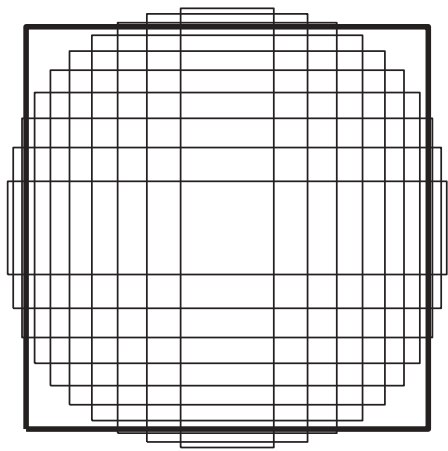

(b)

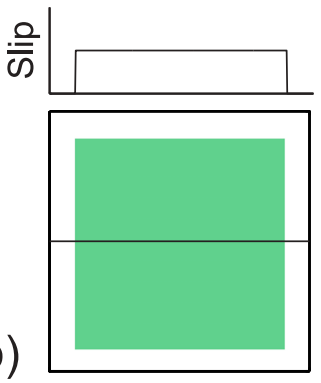

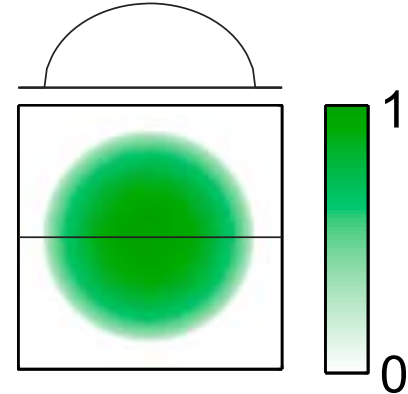

Figure 3. (a) Partitioning of one square source (bold) into 10 rectangles (thin). (b) Slip distribution for one square source, approximation by 10 rectangles and the Madariaga source.

[9] For the computation of coseismic stress changes the tectonic stress field and its orientation is not to be considered, and we may arbitrarily choose the stress field prior to stimulation to be zero. However, to obtain the orientation of optimally oriented fault planes to compute $\triangle \mathrm{CFS}$ we use the linear stress profiles given by Cornet et al. [2007], the orientation of $S_{H, \text { max }}$ is assumed to be $\mathrm{N} 170^{\circ}$. The computation of $\triangle \mathrm{CFS}$ on fault planes optimally oriented for failure is described in detail in King et al. [1994]. If not mentioned otherwise computations of $\triangle \mathrm{CFS}$ are for optimally oriented failure planes. As noted above, computations presented here neither consider changes of pore fluid pressure nor thermal stresses. Obviously, because it is based on seismicity, the $\triangle \mathrm{CFS}$ does not consider either stress changes induced by aseismic slip [e.g., Bourouis and Bernard, 2007; Calò et al., 2011], for which no reliable data exists.

[10] To discriminate the two nodal planes given by the focal mechanism between the fault plane and the auxiliary plane, we apply the Coulomb criterion. The critical pore fluid pressure $p_{c}$ needed to rupture a fault plane is obtained from equation 5 :

$$
p_{c}=\sigma-\frac{\tau}{\mu}
$$

$\sigma$ and $\tau$ are obtained from the orientation of the planes and the tectonic stress field. The critical pore pressure is calculated for both nodal planes; the plane where $p_{c}$ is lower is assumed to be the fault plane.

\section{Partitioning of Source Zones}

[11] In geothermal reservoirs with microseismicity of magnitudes of up to $M_{W}=3$ fault planes with more or less circular shapes could be expected, which is what we assume in the following. Furthermore the slip must reduce to zero at the boundary of the source area to assure continuity and avoid stress singularities. The kinematics and deduced slip distribution of such circular sources were described in Madariaga [1976]. The analytical solutions for computation of displacements due to dislocations by Okada [1992] are for point sources and rectangular sources with constant slip. Due to the linear nature of the stress perturbations, the perturbations by several sources can be added linearly to obtain the cumulative stress perturbation. A widely used approximation for vanishing displacement at the fault boundary is by tapering slip by the superposition of several slip rectangles of similar aspect ratio. As will be shown in the following, this method is not suitable for modeling circular fault planes. To approximate the behavior of circular faults with vanishing displacement at their boundaries, the microseismicity sources were partitioned into superimposed rectangles of varying aspect ratio as shown in Figure 3a. Each rectangle is given the same slip which, summed up over all rectangles, gives the seismic moment of the recorded event. A slip distribution very similar to the elliptical one derived by Madariaga [1976] is obtained by this approximation scheme (Figure $3 b$ ).

[12] The effect on the change of Coulomb failure stress using several superimposed rectangles instead of square sources is analyzed in Figure 4. Here we show the resulting 3D Coulomb failure stress change by one seismic event represented by different slip distributions. The event source is implemented as one square of constant slip, four squares of different sizes representing the tapering used in many studies, 3 rectangles, 10 rectangles and 30 rectangles, respectively. For reference the stress change due to a slip distribution according to the shape of Madariaga's model is implemented using a grid of $40 \times 40$ source tiles (i.e. 1600 sources) with their respective slip. To visualize the $\triangle \mathrm{CFS}$ perturbation in 3D space isosurfaces of $\pm 1 \mathrm{MPa}$ are plotted in Figure 4 along with the slip distribution. For the one square source the isosurfaces occupy only a small volume concentrated on the tips of the shear displacement. For the case of four squares superimposed on the center of the fault we obtain a stress perturbation with tips of the isosurface on the very outer edge of the source. However, comparing with Madariaga's source shows that the stress tip is pointing to the outer edge at the middle of the fault plane. This behavior is much better approximated by three rectangles of different aspect ratios (Figure 4d). Going further to ten rectangles gives very smooth stress perturbations close to that of the Madariaga's source. By increasing the number of rectangles further to 30 only a marginal improvement of the approximation is achieved. However, a feature that cannot be obtained by the approximation by rectangles are the small lobes of opposite stress perturbation close to the fault plane. To sum up, using three rectangles to represent the stress perturbation by a circular Madariaga source yields a much better approximation than using four squares. Additionally it provides faster computation as the effort for calculating $\Delta \mathrm{CFS}$ increases linearly with the number of source rectangles used. At about ten rectangles a reasonable compromise between 


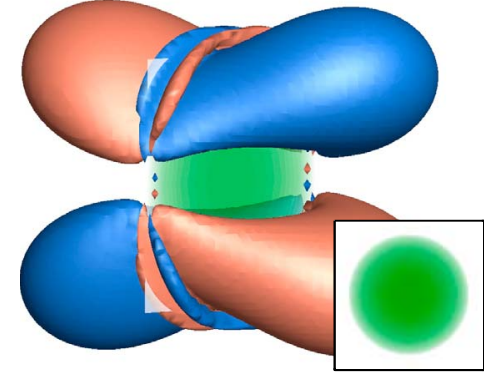

(a) Madariaga

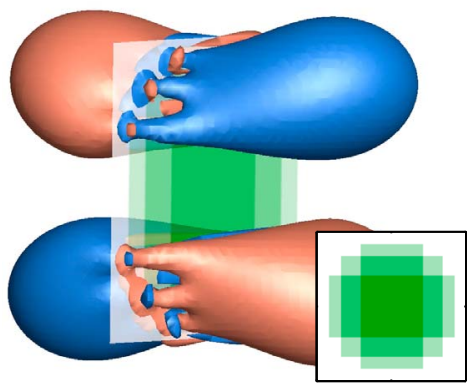

(d) 3 rectangles

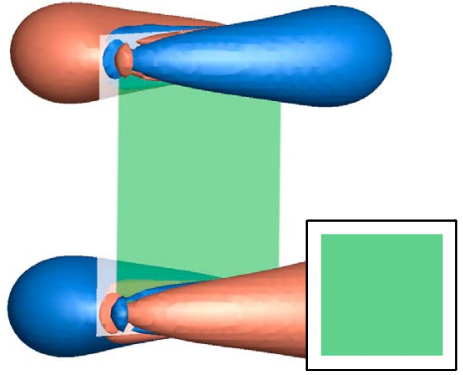

(b) 1 square

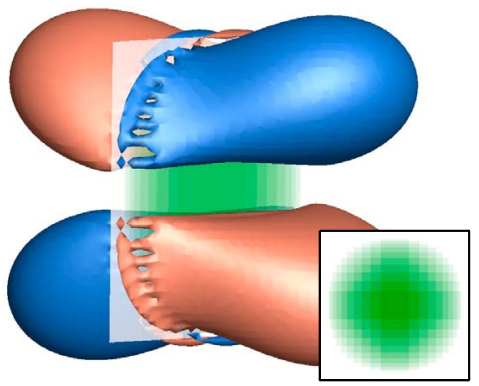

(e) 10 rectangles

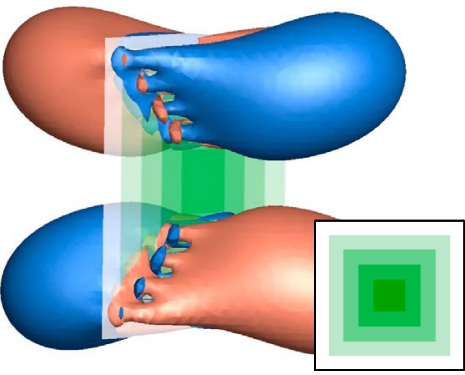

(c) 4 squares

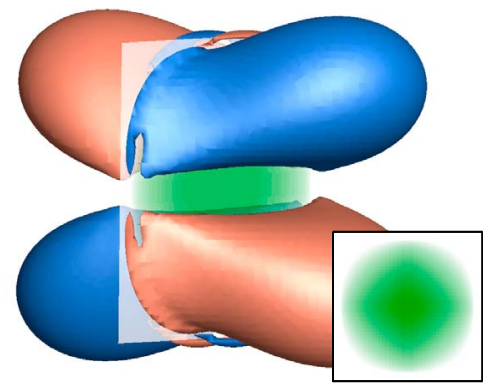

(f) 30 rectangles

Figure 4. (a-f) DeltaCFS isosurfaces of $+1 \mathrm{MPa}$ (red) and $-1 \mathrm{MPa}$ (blue) obtained from different slip distributions (green and insets) for a faulting mechanism with equal seismic moment corresponding to $1 \mathrm{~mm}$ slip on a $10 \times 10 \mathrm{~m}$ square fault.

computational efficiency and accuracy is reached. Thus, in the following this source model is used.

\section{5. $\triangle$ CFS During Stimulation of GPK2}

[13] In order to study the temporal evolution of the $\triangle \mathrm{CFS}$ the data set is split into 14 subsets analogous to Calò et al.
[2011]. They are depicted along with injection rate and wellhead pressure and number of events per hour in Figure 5. Figure 6 shows the temporal evolution of the cumulative $\triangle \mathrm{CFS}$ on a map view at a depth of $4700 \mathrm{~m}$ for each subset. This depth section is about the vertical center of the stimulated volume. During the first nine subsets the cloud of seismic events spreads continuously. The $\triangle \mathrm{CFS}$ perturbation

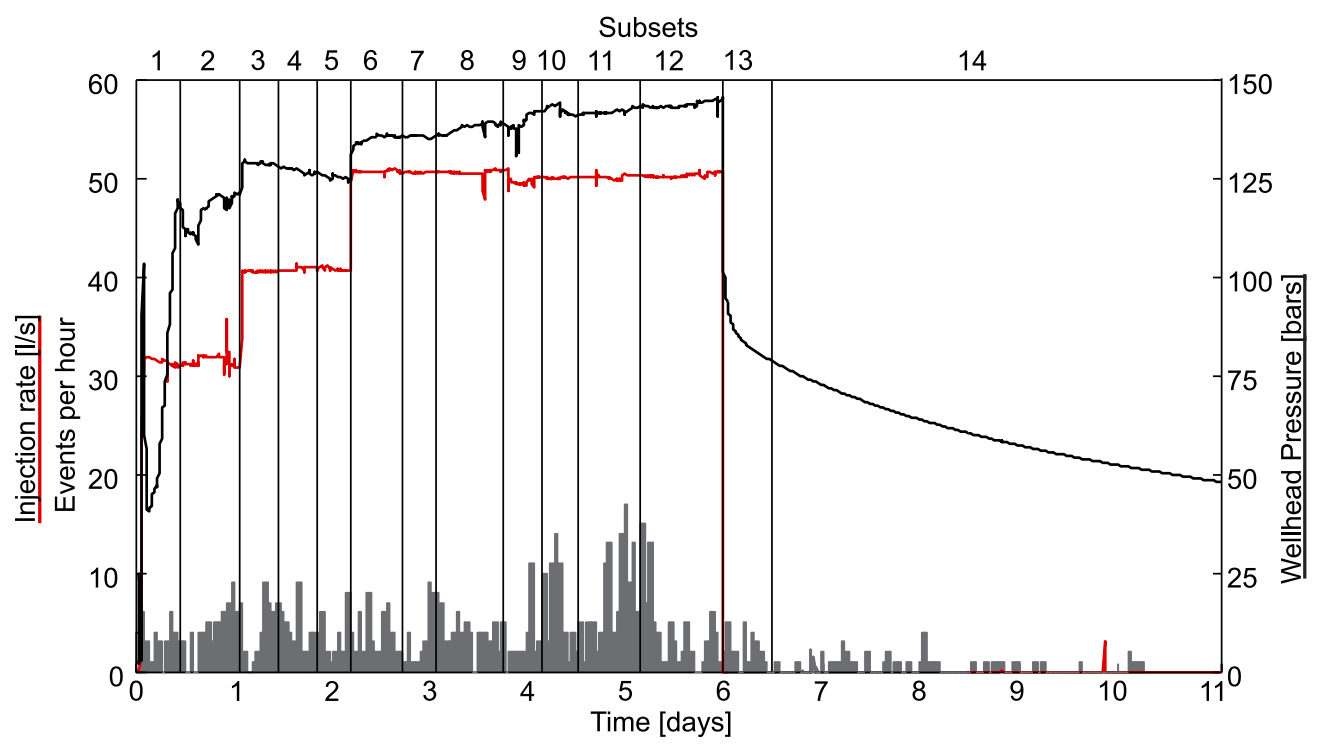

Figure 5. Injection rate, wellhead pressure for the hydraulic stimulation of GPK2 (June/July 2000). Vertical lines mark the times for the 14 snapshots in Figure 6. The bars indicate the event rate per hour $\left(M_{W}>1\right)$ during the experiment. 


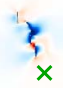

1

4
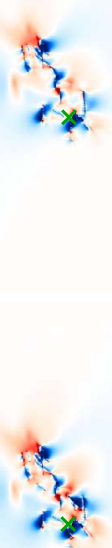

7

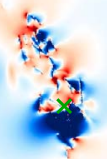

10

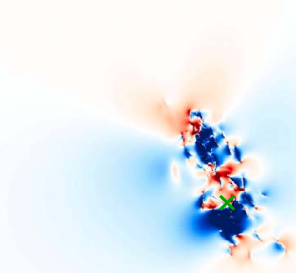

13

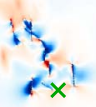

2

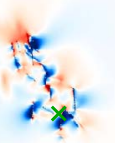

5

8

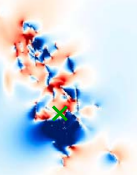

11
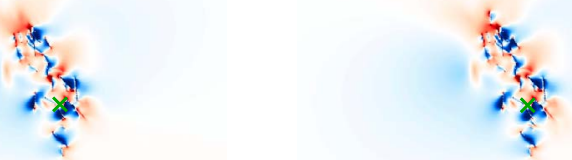

9

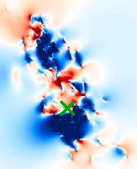

12

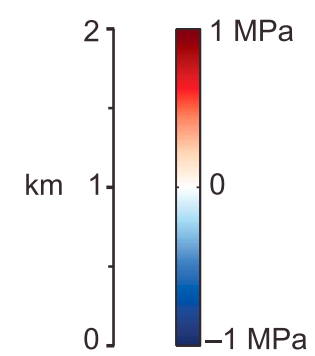

Figure 6. Temporal evolution of cumulative $\triangle$ CFS during stimulation of the well GPK2 after each subset defined in Figure 5. Map view of the Soultz reservoir at $4700 \mathrm{~m}$ depth, the green cross marks the injection point of GPK2. Blue areas are where failure is discouraged $(\Delta \mathrm{CFS}<0)$, red areas are where failure is encouraged $(\triangle \mathrm{CFS}>0)$, with respect to optimal oriented fault planes. 
(a)

(b) (c)

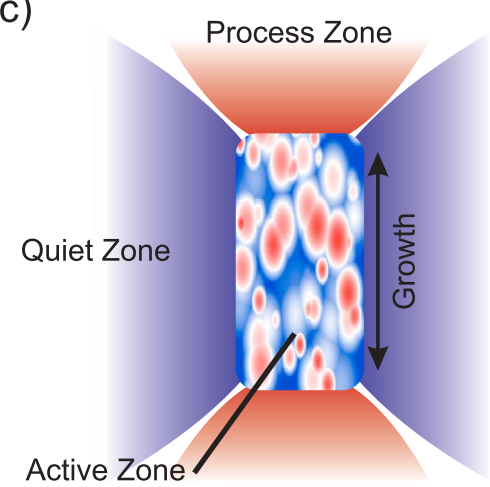

Figure 7. $\triangle$ CFS for optimal oriented fault planes in the Soultz reservoir (a) for one source fault representative of all events [after Dorbath et al., 2008] and (b) for the full catalog of 715 source events, same color scale as in Figure 6. (c) A schematic of the time-evolving coseismic $\triangle$ CFS perturbation in the reservoir.

is dominated by small events that create a pseudo-random pattern of areas with positive and negative $\triangle \mathrm{CFS}$. The stress perturbations reach values on the order of $1 \mathrm{MPa}$, both positive (encouraging failure) and negative (hindering failure), with strong local variations. Areas of strongly positive $\Delta$ CFS are found neighboring to areas of negative $\triangle \mathrm{CFS}$, especially in the central portion of the stimulated region. Subset 10 includes the biggest induced event $\left(M_{W}=2.5\right)$ that dominates a large area with negative $\Delta$ CFS. In the following subsets, a number of relatively large events occur, producing mainly negative $\triangle$ CFS areas in this depth section. In the far field of the reservoir, a large-scale area with negative $\triangle \mathrm{CFS}$ prevails over the whole monitored period with stress release of less then $100 \mathrm{kPa}$. No large areas with positive $\Delta$ CFS are found, it is thus unlikely that slippage of large surface areas is triggered by static stress transfer. On the contrary, it can be speculated that slippage of large surfaces is hindered by stress release on some patches of potential large structures which would lead to segmentation of slip.

[14] In a previous study of static stress transfer at Soultz, Dorbath et al. [2008] assumed that the stress perturbation due to the thousands of microseismic events induced during the stimulation was equal to that of one large event whose seismic moment was the sum of that of all the microseismic events. The orientation and size of that one hypothetical fault plane was chosen to coincide with the geometry of the observed microseismic activity. We compare the distribution of the $\triangle$ CFS obtained from one source according to Dorbath et al. [2008] with the computation of the $\triangle$ CFS according to our method taking into account 715 located events with $M_{W}>1.0$ (Figure 7a). In contrast to Dorbath et al. [2008] we apply the source model presented in section 4 and partition the unique source into 10 rectangles (Figure 4e), while Dorbath et al. [2008] used a tapering method shown in Figure 4c. From comparison of Figures $7 \mathrm{a}$ and $7 \mathrm{~b}$ it is obvious that the approximation to use one single source to represent the stress perturbation due to dislocation is not valid entirely. Both computations deliver fundamentally different results, in particular the central region of the stimulation is essentially free of high stress perturbations whereas many high stress perturbations and undulations result from the detailed computation in this region of the reservoir. However, looking at the far field of coseismic $\triangle$ CFS both results are very much comparable, yielding a large-scale patterns of negative $\triangle$ CFS along the seismic cloud and of positive $\Delta$ CFS at the edges of the seismic cloud. From these observations and with respect to the temporal evolution of the $\Delta$ CFS (Figure 6) we can derive a schematic on the development of the perturbation of $\triangle \mathrm{CFS}$ with three distinct zones (Figure 7c). These are an active zone within the seismic cloud with large variations of $\triangle C F S$ on a local scale, where most of the induced events occur. Furthermore there is a process zone at the tips of the seismic cloud with positive $\triangle \mathrm{CFS}$ encouraging failure, where growth of the microseismic cloud occurs and finally a quiet zone parallel to the cloud where negative $\triangle$ CFS predominates and failure is discouraged. These three distinct zones can also be observed in vertical direction, with a developed process zone also at the top and bottom of the stimulated volume.

\subsection{Sensitivity to Limiting Magnitude}

[15] In Figure 8, we compare $\triangle$ CFS down to different magnitude values contained in the catalog of the focal mechanisms varying from $M_{W}=2.0$ down to $M_{W}=1.0$ at a depth of $4700 \mathrm{~m}$. Also indicated in Figures $8 \mathrm{a}-8 \mathrm{f}$ is the number of events up to a given magnitude and the cumulative seismic moment compared to the total seismic moment recorded during the experiment. For events down to $M_{W}=1.6$ about $60 \%$ of the cumulative seismic moment is included in the perturbation of $\triangle \mathrm{CFS}$. The $\triangle \mathrm{CFS}$ perturbation of the largest recorded event with magnitude 2.5 is remarkable. Its contribution to $\triangle$ CFS dominates a region of several hundred meters radius (bottom of subplots in Figure 8). Figure 9 shows the mean of the relative variation of $\triangle \mathrm{CFS}$ for a reduced catalog down to $M_{W \text {,limit }}$ compared to the full catalog down to $M_{W}=1.0$ after

$$
\delta=\frac{1}{n} \sum_{n=0}^{N}\left|\frac{\Delta C F S_{1.0}-\Delta C F S_{M_{W, \text { Iinit }}} \mid}{\Delta C F S_{1.0}}\right|,
$$

with $N$ the number of points where $\triangle \mathrm{CFS}$ is calculated. The difference of computed values of $\Delta \mathrm{CFS}$ reduces linearly with magnitudes contained in the catalog. Small events therefore contribute a significant amount of static stress transfer. Small 
(a)

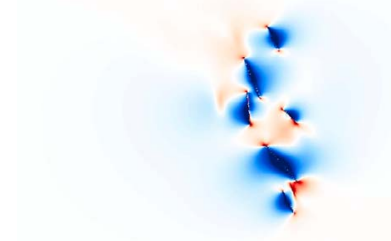

$M_{\text {w.limit }}=2.0$

26 Events, $26 \% \mathrm{M}_{0}$

(d)

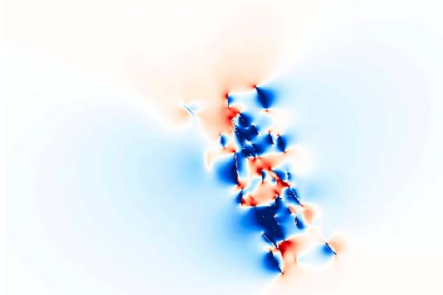

$\mathrm{M}_{\mathrm{W}, \text { imiti }}=1.4$

312 Events, $73 \% \mathrm{M}_{0}$ (b)

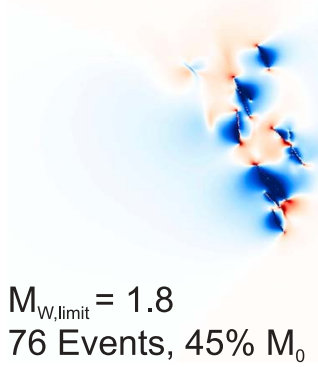

(e)

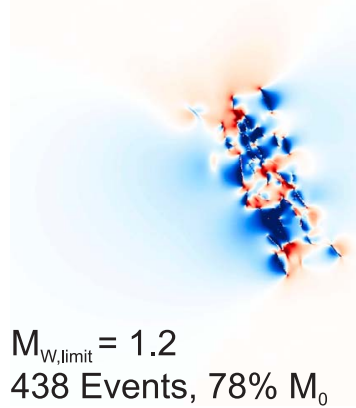

(c)

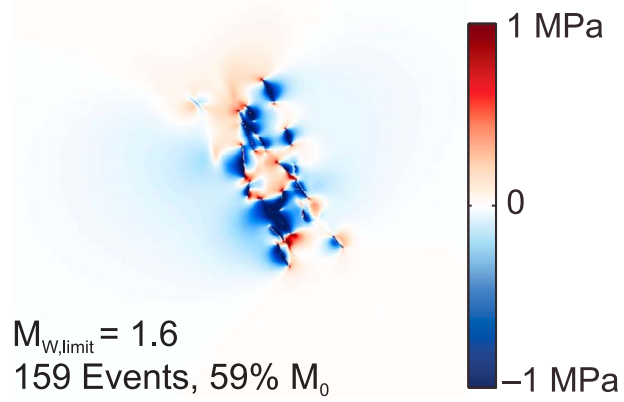

(f)

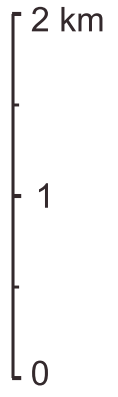

$M_{\text {w,limit }}=1.0$

715 Events, $85 \% \mathrm{M}_{0}$

Figure 8. (a-f) Map view of $\triangle \mathrm{CFS}$ at $z=4700 \mathrm{~m}$ for a subset of the full catalog, where the magnitude $M_{W \text {,limit }}$ down to which events are contained in the catalog varies. The number of events of each subset and the cumulative seismic moment relative to the total recorded moment is given in each image. Optimal oriented fault planes are assumed.

events cause a smaller stress perturbation, but there are a greater number of them. The significant effect of small earthquakes for static stress transfer is in full agreement with the study by Helmstetter et al. [2005] on the triggering potential of small earthquakes. They find that for a set of events on a fractal fracture network of dimension $D$ with a GutenbergRichter law with $b \approx D / 2$ [Aki, 1981; Chen et al., 2006] small events areas important for triggering as large events. However, including even smaller events will contribute to the $\triangle \mathrm{CFS}$ perturbation only very locally, on a scale where errors in location dominate any possible conclusion.

\subsection{Triggering Potential and Stress Drop}

[16] In this section we discuss the distribution of $\Delta$ CFS values obtained from a constant stress drop and its implication for triggering. We study the effect of varying stress drop and make some preliminary conclusions. Then we analyze the distribution of $\triangle \mathrm{CFS}$ on the hypocenters of the microseismic events to investigate how the occurrence of microseismicity is influenced by $\triangle \mathrm{CFS}$. For a given event we compute the cumulative $\triangle \mathrm{CFS}$ of all previous events at its located hypocenter. We do this for each event in our data set and analyze two scenarios. In the first we compute $\Delta \mathrm{CFS}$ for optimally oriented fault planes, as in the calculations before. In the second calculation we compute $\triangle \mathrm{CFS}$ at the hypocenter using the orientation of the fault plane of the given event, to derive normal and shear stresses and finally the value of $\triangle \mathrm{CFS}$ (Figure 10a). For both fracture orientations we obtain almost a normal distribution centered on $\triangle \mathrm{CFS}=0$.

[17] All results presented above have been acquired using the assumption of a constant stress drop of $1 \mathrm{MPa}$. For the stimulation of the granitic reservoir at Basel, stress drops were quantitatively analyzed by Goertz-Allmann et al. [2011]. They

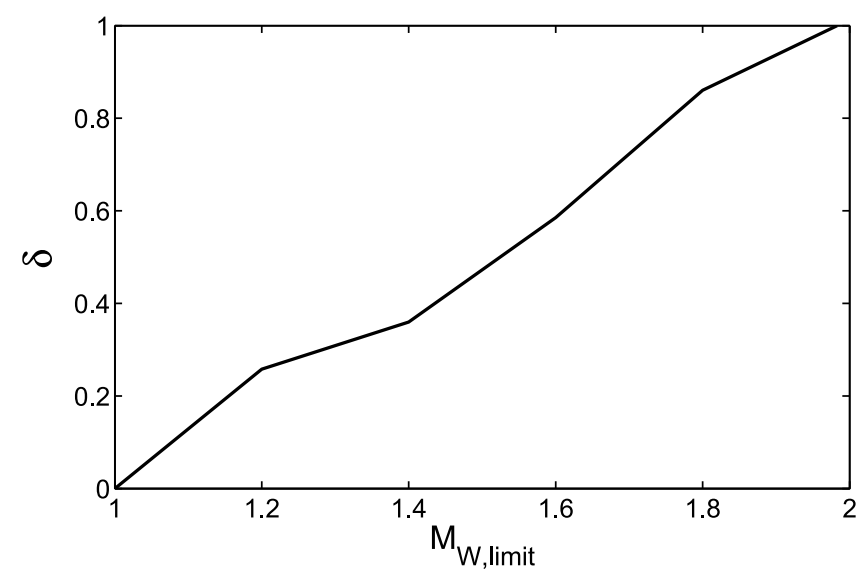

Figure 9. Relative error of $\triangle \mathrm{CFS}$ for a reduced catalog down to $M_{W \text {,limit }}$ compared to the full catalog down to $M_{W}=$ 1.0 after equation (8). 

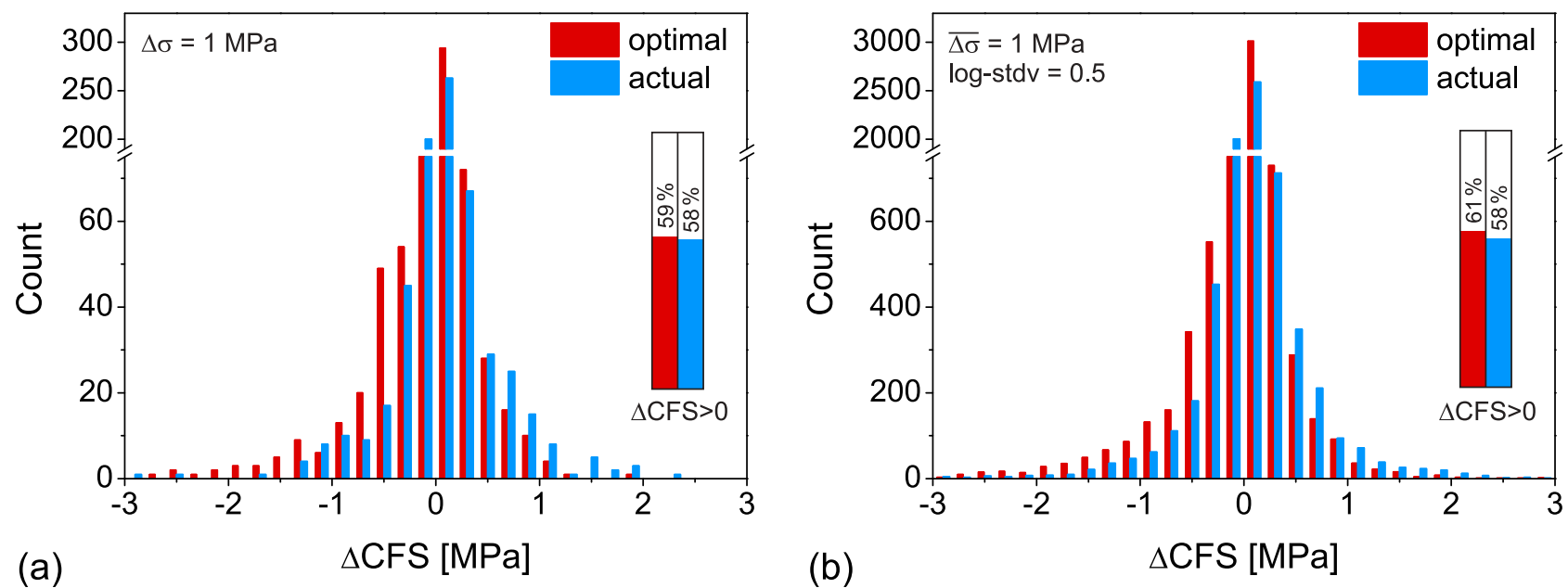

Figure 10. Distribution of $\triangle \mathrm{CFS}$ at the hypocenters for fault planes optimally oriented for failure (red) and for the actual orientations of fault planes (blue). Stress drop is (a) constant $1 \mathrm{MPa}$ and (b) log-normal distributed about $1 \mathrm{MPa}$ using 10 runs with different random seeds. Note the break in the y axis.

found the stress drop to vary over two orders of magnitude around a mean value of $2.3 \mathrm{MPa}$. In order to analyze the impact of our assumption on stress drop, we compute $\triangle \mathrm{CFS}$ using random stress drops for each event. The stress drops are chosen using a log-normal distribution to resemble the distribution of stress drop values obtained by Goertz-Allmann et al. [2011], with a log-mean of $\Delta \sigma=1 \mathrm{MPa}$ and a logstandard deviation of 0.5 . The computation is repeated 10 times using different random number seeds (Figure 10b). We obtain relatively large variations of values of $\triangle$ CFS for each single fracture. However, the overall behavior of $\triangle \mathrm{CFS}$ is statistically the same for different sets of stress drop including the constant stress drop of $1 \mathrm{MPa}$. We therefore conclude that the approximation of constant stress drop is acceptable for our analysis. Overall we find that $61 \%$ and $58 \%$ of the events occur in areas of positive $\triangle \mathrm{CFS}$ for optimal and the actual orientation of faults, respectively. A closer look at the distributions on $\triangle \mathrm{CFS}$ reveals that optimal orientation yields more negative values, especially below $-0.5 \mathrm{MPa}$, whereas the actual fracture orientation yields more positive values above $+0.5 \mathrm{MPa}$. The variation observed is interpreted as a dependency of the triggering potential on the relative fracture orientations. When calculating the stress transfer for similarly aligned fractures, e.g. actual fracture families, constructive superposition of stress transfer is more likely than for dissimilar fracture orientations, e.g. the optimal orientation given by the stress field. Therefore similarly aligned fractures are more efficient at triggering than randomly oriented fractures.

\subsection{Triggering: An Example}

[18] For further analysis of potential triggering of seismicity by static stress transfer we analyze a cluster of relatively large events $\left(1<M_{W}<2.2\right)$ that occurred after shut-in during a period of four days, when the general seismic activity already declined. The cluster is located at the top of the northwestern edge of the stimulated volume (Figure 1). It was noticed by Cuenot et al. [2008] for its large ratio of high- magnitude events to low-magnitude events and its detached location at the edge of the reservoir. Inter-event times range from six minutes to more then one day, so dynamic triggering can be ruled out. Twelve focal mechanisms from this cluster are contained in our data set. All approximately share the same focal mechanism (Figure 11a). Hence it is likely, that each event ruptured a different segment of the same large scale structure. This structure coincides very well with a major fault structure named VSP-GPK1-3490 and GPK3FZ4770 from the 3D geological model by Sausse et al. [2010], identified from a VSP study and image logs of the wells. This structure is known to hydraulically connect the wells GPK1, GPK2 and GPK3 and is probably responsible for the good hydraulic communication of these wells as revealed by tracer tests [Sanjuan et al., 2006]. Under the assumption of a fault plane common to all events of the cluster, we computed a mean focal plane (strike N135 ${ }^{\circ}$, dip $70^{\circ}$ ) and projected all derived focal planes onto that plane, for computation of $\triangle \mathrm{CFS}$. The distance of each focal plane to the mean plane was below $60 \mathrm{~m}$, and within the location errors which underpins the assumption. The orientation of the mean plane was assumed for the computation of normal and shear stresses to obtain $\triangle$ CFS. Figures $11 \mathrm{~b}-11 \mathrm{e}$ are snapshots of the 3D $\triangle \mathrm{CFS}$ with isosurfaces at $0.3 \mathrm{MPa}$. After the first three events (Figure 11b) a distinct pattern of matching jigsaw puzzle pieces of ruptured fault segments evolves. Each event appears to rupture a different slip patch, generating regions of positive $\triangle \mathrm{CFS}$ at its edge, which in turn propagates shearing along the fault zone by triggering the next event. Rupture propagation by slippage of neighboring slip patch has been already observed by Phillips et al. [2002] on a reservoir scale. Due to the spatial proximity and the shared orientation of slip patches on a fault zone, static stress transfer is very effective. Rupture propagation is maintained during the whole sequence, with some areas being ruptured more than once.

[19] Assessing the role of triggering by static stress transfer versus the role of pore pressure increases for the propagation 

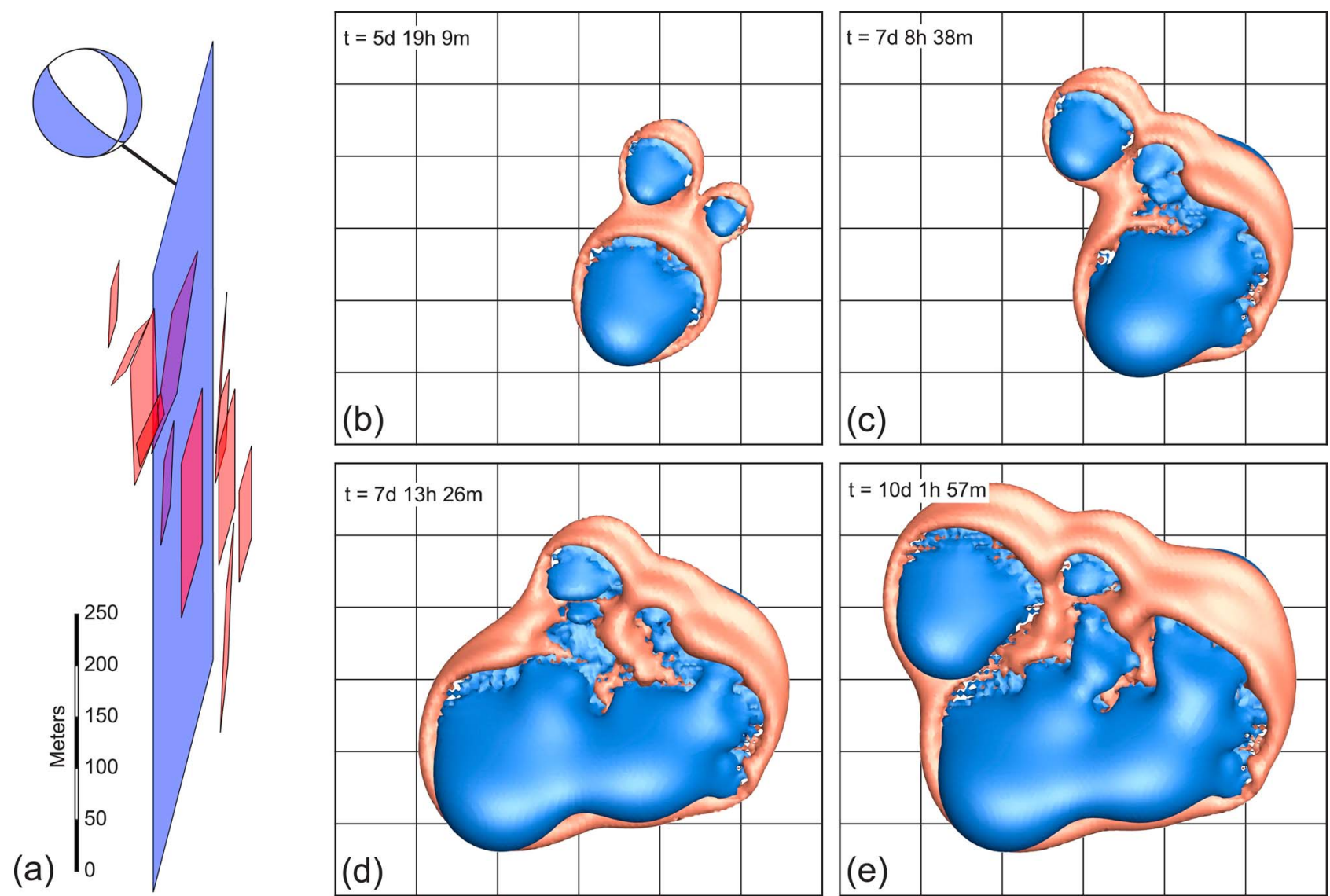

Figure 11. Cluster of 12 events that occurred during four days after shut-in. (a) Determined focal planes (red) and a mean fault plane (blue) on which the focal planes were projected. (b-e) Isosurfaces of $+0.3 \mathrm{MPa}$ (red) and $-0.3 \mathrm{MPa}$ (blue) for different times (given relative to the beginning of injection) during the sequence after $3,6,8$ and all 12 events, respectively.

of the cluster is very difficult. The cluster occurred about $900 \mathrm{~m}$ away from the open hole section of GPK2. The cluster of events could be associated with a large-scale fault structure with high transmissivity which is unlikely to allow high pore pressure build-up. Additionally, this cluster occurred after shut-in of the well and beyond the previous front of microseismic events (cf. Figure 1). Neither a reliable model for the propagation of pore pressure, especially after the shut-in of the well nor measurements of pressure away from the injection well exist. However, it is plausible that pore pressure still increased at the clusters location, also after shut-in [McClure and Horne, 2012; Baisch et al., 2010]. At the well GPK1, at a distance of about $1400 \mathrm{~m}$ to the open hole section of GPK2, pressure was monitored but no response could be recorded during stimulation. During a later stimulation of GPK3 (ca. $600 \mathrm{~m}$ away from GPK2) in 2003 the maximum pressure response measured in GPK2 was about $4 \mathrm{MPa}$ before the dual stimulation with pumping in GPK2 began [Dorbath et al., 2009]. At that point seismicity progressed from GPK3 to beyond GPK2 and through a volume already stimulated during the stimulation of GPK2 in 2000. Following these observations the pore pressure at the cluster is certainly well below $4 \mathrm{MPa}$ and probably below $2 \mathrm{MPa}$ with a small pressure gradient. Thus, the static stress transfer contributes a considerable amount to the overall perturbation of stress, at least at the edges of individual slipping patches.

\section{Discussion}

[20] From the seismic recordings of the stimulation more than 14,000 events could be located, but only from 715 events focal mechanism could be derived due to their signalto-noise ratio. It is therefore important to note that potentially some fracture families did not generate large enough events, and their focal mechanisms are not represented in our study.

[21] The analysis is based on the assumption of an elliptical slip distribution on a penny-shaped crack given by the Madariaga [1976] model. Estimations of slip distribution and actual shape of a sheared crack cannot be obtained from fluid induced seismicity due to their low magnitudes. The methodology applied allows calculation of arbitrary geometries. It can be speculated that the slipping areas are bounded by locked portions on a fault surface, leading to fragmentation of slip with temporal and spatial clustering of events. Slippage might also be stopped at intersections with other cracks, leading to angular areas of slippage.

[22] Uncertainties of location and stress drop of the events are of large importance. As rupture dimensions $(\approx 150 \mathrm{~m})$ are 
in the order of the location error $(\approx 50 \mathrm{~m})$ and stress drops generally vary over two orders of magnitude great care must be taken on the interpretation of the results. We therefore analyze the $\triangle \mathrm{CFS}$ values in a statistical sense to confirm the robustness of the results. For varying stress drop this is given by the trade-off between small slipping areas with large slip, and large slipping areas with small slip given a certain moment magnitude. The first yields higher stress perturbations with smaller perturbed volume while the latter yields larger volumes with a smaller stress perturbation. These competing mechanisms equalize each other out within certain limits. It has been shown both, statistically and by an example, that triggering by static stress transfer is possible also in the environment of hydraulic stimulations. Also, if a slip patch is at the verge of failure e.g. by a perturbation of stress by pore fluid pressure increase, static stress transfer might deliver the last bit of stress perturbation necessary for rupture. Due to the large local scattering of the static stress transfer we cannot predict the growth of the seismic cloud due to triggering.

[23] Above we show that triggering by static stress transfer is of little importance in a volumetric reservoir but it can be quite efficient if the seismic response is confined to single large scale structures. The latter is exemplified on a cluster of events within the Soultz reservoir. However, it is still under debate whether EGS reservoirs are dominated by single large scale structures or by a volumetric network of fractures. In general, the locations and focal mechanisms in our data set of the stimulation of GPK 2 suggest that the reservoir created by the stimulation is volumetric in structure rather than dominated by one or two major structures. This is supported by the relocations with small location errors, furthermore the focal mechanisms show distinct families of fractures which are distributed over the whole reservoir volume. Specifically, there are fracture families distributed over the whole seismic cloud with fault plane orientations almost perpendicular to the major axis of the seismic ellipsoid (see Figure 1). Furthermore, the b-value of 1.23 obtained by Dorbath et al. [2009] indicates a volumetric fracture network with a fractal dimension $D>2$, whereas stimulations of GPK3 and GPK4 have b-values indicating to fracture networks of fractal dimension $D \approx 2$ using the relation of b-value and fractal dimension of a fracture network by Aki [1981]. We therefore regard the reservoir created by the stimulation of GPK2 as volumetric as suggested by the locations and orientation of the focal mechanisms. On the other hand, due to inevitable location errors, events occurring on a plane will be apparently located in a volume rather than at their actual position on the plane. Hence, our method tends to underestimate the stress interaction.

[24] Static stress transfer after seismic events was incorporated in several numerical codes simulating fracture of fault segments by elevated pore pressure. Usually slip patches are considered in different kinds of geomechanical simulations and eventually are brought to failure. Upon failure stresses are redistributed to neighboring slip patches. To compute the displacement field and derive changes to the stress tensor arising from simulated slip, the codes, for example, by McClure and Horne [2012] and Yamashita [1998] use numerical and analytical methods, respectively. Baisch et al. [2010] used a generic stress redistribution pattern for stress release at the failing slip patch and stress increase in neighboring slip patches. A number of other codes incorporating static stress transfer are currently under development by the community. All of these simulators are able to propagate failure along larger fractures and, by adding of slip of subsequently failing slip patches, are able to predict event magnitudes. The latter two codes are also used to predict $b$-values. Our study has shown, that considering static stress transfer is a viable means to propagate shearing of individual segments over a large fault. However, application of static stress transfer on a 3D fracture network may be difficult due to large local variations of the stress perturbation.

\section{Conclusions}

[25] We use a computationally efficient method to analytically compute coseismic changes of Coulomb failure stress due to dislocations in the volume of a reservoir. This method accounts for an elliptical slip distribution on a circular fracture. We applied this approach on a data set of 715 focal mechanisms obtained from the stimulation of GPK2 in Soultz. Changes of Coulomb failure stress of the order of $\pm 1 \mathrm{MPa}$ were obtained and showed strong local variations due to the great number of events. Due to these variations a statistical interpretation has to be applied, rather than a deterministic one. However, static stress changes develop a consistent pattern during the stimulation with an emerging process zone, an active zone and a quiet zone. We showed that the local stress perturbation by dislocations estimated from microseismicity induced by hydraulic stimulation cannot be depicted by one large source, except if our interest is in the far field zone of the reservoir, where $\triangle \mathrm{CFS}$ is more uniform. On the contrary, our analysis shows a fundamentally different distribution of the stress perturbation and much more internal structure when analyzed in high detail. The values of $\triangle \mathrm{CFS}$ at the event hypocenters just before the events show distribution about $0 \mathrm{MPa}$ with about $3 \%$ of events with $\triangle \mathrm{CFS}>1 \mathrm{MPa}$. In a volumetric reservoir $\triangle \mathrm{CFS}$ by dislocation is thus only a minor contribution to the whole stress perturbation induced by stimulation, compared to e.g. an increase of pore fluid pressure. The latter typically is in the order of a few $\mathrm{MPa}$, even at larger distance from the stimulated wells [Dorbath et al., 2009, Figure 6]. The study by Langenbruch et al. [2011] supports this result by showing that induced seismicity can be described by a Poisson process, i.e. the events are not causally related to each other. However, inevitable relocation errors tend to bias these results toward underestimating stress interaction. If more events are located on a single plane, the possibility of constructive interference of $\triangle \mathrm{CFS}$ will increase. Additionally we showed the triggering potential of neighboring slip patches on a larger fault zone and conclude that in such cases static stress transfer may propagate rupture, as proposed by Phillips et al. [2002].

[26] Acknowledgments. The work was supported by the European Commission (FP7 project GEISER, grant agreement 241321) and by EnBW Energie Baden-Württemberg AG. Comments by Emmanuel Gaucher, Rebecca Harrington, Oliver Heidbach, and Cornelius Langenbruch are greatly acknowledged. We especially express our appreciation to Mark McClure for his thorough review of the manuscript.

\section{References}

Aki, K. (1981), A probabilistic synthesis of precursory phenomena, in Earthquake Prediction: An International Review, edited by D. W. Simpson and P. G. Richards, pp. 566-574, AGU, Washington, D. C. 
Baisch, S., R. Vörös, E. Rothert, H. Stang, R. Jung, and R. Schellschmidt (2010), A numerical model for fluid injection induced seismicity at Soultz-sous-Forêts, Int. J. Rock. Mech. Min., 47(3), 405-413, doi:10.1016/j. ijrmms.2009.10.001.

Bourouis, S., and P. Bernard (2007), Evidence for coupled seismic and aseismic fault slip during water injection in the geothermal site of Soultz (France), and implications for seismogenic transients, Geophys. J. Int., 169(2), 723-732, doi:10.1111/j.1365-246X.2006.03325.x.

Bruel, D. (2002), Impact of induced thermal stresses during circulation tests in an engineered fractured geothermal reservoir: Example of the Soultzsous-Forets European hot fractured rock geothermal project, Rhine Graben, France, Oil GasSci. Technol., 57(5), 459-470.

Calò, M., C. Dorbath, F. H. Cornet, and N. Cuenot (2011), Large-scale aseismic motion identified through 4-D P-wave tomography, Geophys. J. Int., 186(3), 1295-1314, doi:10.1111/j.1365-246X.2011.05108.x.

Catalli, F., M. Cocco, R. Console, and L. Chiaraluce (2008), Modeling seismicity rate changes during the 1997 Umbria-Marche sequence (central Italy) through a rate- and state-dependent model, J. Geophys. Res., 113, B11301, doi:10.1029/2007JB005356.

Charléty, J., N. Cuenot, L. Dorbath, C. Dorbath, H. Haessler, and M. Frogneux (2007), Large earthquakes during hydraulic stimulations at the geotherma site of Soultz-sous-Forêts, Int. J. Rock. Mech. Min., 44(8), 1091-1105, doi:10.1016/j.ijrmms.2007.06.003.

Chen, C. C., W. C. Wang, Y. F. Chang, Y. M. Wu, and Y. H. Lee (2006), A correlation between the b-value and the fractal dimension from the aftershock sequence of the 1999 Chi-Chi, Taiwan, earthquake, Geophys. J. Int., 167, 1215-1219, doi:10.1111/j.1365-246X.2006.03230.x.

Cornet, F. H., T. Bérard, and S. Bourouis (2007), How close to failure is a granite rock mass at a $5 \mathrm{~km}$ depth, Int. J. Rock Mech. Min., 44, 47-66, doi:10.1016/j.ijrmms.2006.04.008.

Cuenot, N., C. Dorbath, and L. Dorbath (2008), Analysis of the microseismicity induced by fluid injections at the EGS site of Soultz-sous-Forets (Alsace, France): Implications for the characterization of the geothermal reservoir properties, Pure Appl. Geophys., 165(5), 797-828, doi:10.1007/ s00024-008-0335-7.

Dieterich, J. (1994), A constitutive law for rate of earthquake production and its application to earthquake clustering, J. Geophys. Res., 99(B2), 2601-2618, doi:10.1029/93JB02581.

Dorbath, L., N. Cuenot, and R. Stein (2008), Coulomb stress change by the stimulation of GPK2 and the orientation of the seismicity induced by the stimulation of GPK3, paper presented at EHDRA scientific conference, Eur. Hot Dry Rock Assoc., Soultz-sous-Forêts, France.

Dorbath, L., N. Cuenot, A. Genter, and M. Frogneux (2009), Seismic response of the fractured and faulted granite of Soultz-sous-Forêts (France) to $5 \mathrm{~km}$ deep massive water injections, Geophys. J. Int., 177(2), 653-675, doi:10.1111/j.1365-246X.2009.04030.x.

Dyer, B. (2000), Soultz GPK2 stimulation June/July 2000, seismic monitoring, report, Semore Seismic, Socomine, France.

Eshelby, J. D. (1957), The determination of the elastic field of an ellipsoidal inclusion, and related problems, Proc. R. Soc. A, 241(1226), 376-396, doi:10.1098/rspa.1957.0133.

Evans, K., A. Zappone, T. Kraft, N. Deichmann, and F. Moia (2012), A survey of the induced seismic responses to fluid injection in geothermal and $\mathrm{CO}_{2}$ reservoirs in Europe, Geothermics, 41, 30-54, doi:10.1016/j. geothermics.2011.08.002.

Felzer, K. R., and E. E. Brodsky (2006), Decay of aftershock density with distance indicates triggering by dynamic stress, Nature, 441(7094), 735-738, doi:10.1038/nature04799.

Genter, A., K. Evans, N. Cuenot, D. Fritsch, and B. Sanjuan (2010), Contribution of the exploration of deep crystalline fractured reservoir of Soultz to the knowledge of enhanced geothermal systems (EGS), C. R. Geosci., 342(7-8), 502-516, doi:10.1016/j.crte.2010.01.006.

Goertz-Allmann, B. P., A. Goertz, and S. Wiemer (2011), Stress drop variations of induced earthquakes at the Basel geothermal site, Geophys. Res. Lett., 38, L09308, doi:10.1029/2011GL047498.

Hardebeck, J. L., J. J. Nazareth, and E. Hauksson (1998), The static stress change triggering model: Constraints from two Southern California aftershock sequences, J. Geophys. Res., 103(B10), 24427-24437, doi:10.1029/ 98JB00573.

Helmstetter, A., Y. Y. Kagan, and D. D. Jackson (2005), Importance of small earthquakes for stress transfers and earthquake triggering, J. Geophys. Res., 110, B05S08, doi:10.1029/2004JB003286.
Jost, M. L., T. Büßelberg, Ö. Jost, and H. P. Harjes (1998), Source parameters of injection-induced microearthquakes at $9 \mathrm{~km}$ depth at the KTB deep drilling site, Germany, Bull. Seismol. Soc. Am., 88, 815-832.

Kanamori, H. (1977), The energy release in great earthquakes, J. Geophys. Res., 82(20), 2981-2987, doi:10.1029/JB082i020p02981.

King, G. C. P., R. S. Stein, and J. Lin (1994), Static stress changes and the triggering of earthquakes, Bull. Seismol. Soc. Am., 84(3), 935-953.

Klein, F. W. (1978), Hypocenter location program HYPOINVERSE, Part1: User guide to version 1,2,3 and 4, U.S. Geol. Surv. Open File Rep., 78-694.

Kohl, T., and T. Mégel (2007), Predictive modeling of reservoir response to hydraulic stimulations at the European EGS site Soultz-sous-Forets, Int. J. Rock Mech. Min., 44, 1118-1131, doi:10.1016/j.ijrmms.2007.07.022.

Langenbruch, C., C. Dinske, and S. A. Shapiro (2011), Inter event times of fluid induced earthquakes suggest their Poisson nature, Geophys. Res. Lett., 38, L21302, doi:10.1029/2011GL049474.

Madariaga, R. (1976), Dynamics of an expanding circular fault, Bull. Seismol. Soc. Am., 66(3), 639-666.

McClure, M. W., and R. N. Horne (2012), Investigation of injectioninduced seismicity using a coupled fluid flow and rate/state friction model, Geophysics, 76, WC183, doi:10.1190/geo2011-0064.1.

Meller, C., T. Kohl, and E. Gaucher (2012), Approach for determination of the failure probability of fractures at the Soultz-Sous-Forêts EGS project, in 37th Workshop on Geothermal Reservoir Engineering 2012, pp. 843-850, Curran Assoc., Red Hook, N. Y.

Okada, Y. (1992), Internal deformation due to shear and tensile faults in a half-space, Bull. Seismol. Soc. Am., 82(2), 1018-1040.

Orlecka-Sikora, B., E. Papadimitriou, and G. Kwiatek (2009), A study of the interaction among mining-induced seismic events in the Legnica-Glogów Copper District, Poland, Acta Geophys., 57(2), 413-434, doi:10.2478/ s11600-008-0085-z.

Phillips, W. S., J. T. Rutledge, L. S. House, and M. C. Fehler (2002), Induced microearthquake patterns in hydrocarbon and geothermal reservoirs: Six case studies, Pure Appl. Geophys., 159(1), 345-369.

Prejean, S. G., D. P. Hill, E. E. Brodsky, S. E. Hough, M. J. S. Johnston, S. D. Malone, D. H. Oppenheimer, A. M. Pitt, and K. B. Richards-Dinger (2004), Remotely triggered seismicity on the United States west coast following the M-w 7.9 Denali fault earthquake, Bull. Seismol. Soc. Am., 94(6), S348-S359, doi:10.1785/0120040610.

Sanjuan, B., J.-L. Pinault, P. Rose, A. Gérard, M. Brach, G. Braibant, C. Crouzet, J.-C. Foucher, A. Gautier, and S. Touzelet (2006), Tracer testing of the geothermal heat exchanger at Soultz-sous-Forêts (France) between 2000 and 2005, Geothermics, 35(5-6), 622-653, doi:10.1016/ j.geothermics.2006.09.007.

Sausse, J., C. Dezayes, L. Dorbath, A. Genter, and J. Place (2010), 3D model of fracture zones at Soultz-sous-Forêts based on geological data, image logs, induced microseismicity and vertical seismic profiles, $C$. $R$. Geosci., 342(7-8), 531-545, doi:10.1016/j.crte.2010.01.011.

Shapiro, S. A., E. Rothert, V. Rath, and J. Rindschwentner (2002), Characterization of fluid transport properties of reservoirs using induced microseismicity, Geophysics, 67, 212-220, doi:10.1190/1.1451597.

Stein, R. S., A. A. Barka, and J. H. Dieterich (1997), Progressive failure on the North Anatolian fault since 1939 by earthquake stress triggering, Geophys. J. Int., 123(3), 594-604, doi:10.1111/j.1365-246X.1997.tb05321.x.

Toda, S., and R. Stein (2003), Toggling of seismicity by the 1997 Kagoshima earthquake couplet: A demonstration of time-dependent stress transfer, J. Geophys. Res., 108(B12), 2567, doi:10.1029/2003JB002527.

Wang, R., F. L. Martín, and F. Roth (2003), Computation of deformation induced by earthquakes in a multi-layered elastic crust-FORTRAN programs EDGRN/EDCMP, Comput. Geosci., 29(2), 195-207, doi:10.1016/ S0098-3004(02)00111-5.

Weidler, R., A. Gérard, R. Baria, J. Baumgärtner, and R. Jung (2002), Hydraulic and micro-seismic results of a massive stimulation test at $5 \mathrm{~km}$ depth at the European Hot-Dry-Rock test site Soultz, France, in 27th Workshop on Geothermal Reservoir Engineering, pp. 95-100, Curran Assoc., Red Hook, N. Y.

Xiong, X., B. Shan, Y. Zheng, and R. Wang (2010), Stress transfer and its implication for earthquake hazard on the Kunlun fault, Tibet, Tectonophysics, 482(1-4), 216-225, doi:10.1016/j.tecto.2009.07.020.

Yamashita, T. (1998), Simulation of seismicity due to fluid migration in a fault zone, Geophys. J. Int., 132(3), 674-686, doi:10.1046/j.1365246X.1998.00483.X. 